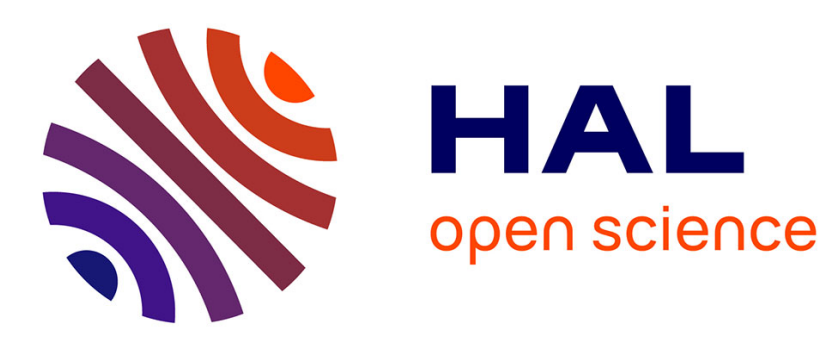

\title{
Reactive-homeostasis as a cybernetic model of the silhouette effect of denial of pregnancy
}

Patrick Sandoz

\section{To cite this version:}

Patrick Sandoz. Reactive-homeostasis as a cybernetic model of the silhouette effect of denial of pregnancy. Medical Hypotheses, 2011, 77 (5), pp.782 - 785. hal-02300177

\section{HAL Id: hal-02300177 \\ https://hal.science/hal-02300177}

Submitted on 29 Sep 2019

HAL is a multi-disciplinary open access archive for the deposit and dissemination of scientific research documents, whether they are published or not. The documents may come from teaching and research institutions in France or abroad, or from public or private research centers.
L'archive ouverte pluridisciplinaire $\mathbf{H A L}$, est destinée au dépôt et à la diffusion de documents scientifiques de niveau recherche, publiés ou non, émanant des établissements d'enseignement et de recherche français ou étrangers, des laboratoires publics ou privés. 


\title{
Reactive-homeostasis as a cybernetic model of the silhouette effect of denial of pregnancy
}

\author{
P. Sandoz, $\mathrm{PhD}$ \\ FEMTO-ST Institute, Université de Franche-Comté, UMR CNRS 6174, \\ 25000 Besançon, France.
}

Correspondence author:

Dr. Patrick Sandoz

Institut FEMTO-ST / DMA

24, rue de l'Epitaphe,

25000 Besançon, France

Phone: +33 381666420

Fax : + 33381666700

e-mail : patrick.sandoz@univ-fcomte.fr 


\begin{abstract}
In a woman presenting a pervasive denial of pregnancy, it happens that abdominal swelling is significantly reduced if not completely absent. In such cases, the announcement of the pregnancy to the unaware woman by a physician is often sufficient to trigger the spontaneous appearance of a normal silhouette of pregnancy with abdominal prominence. The pregnancy announcement acts as an input signal applied to the regulation mechanisms of the body with the consequence that the output signal; i.e. the silhouette of the pregnant woman; turns spontaneously from an abnormal shape to a normal one.

By applying a system-based analysis to these observations, the brain appears clearly to be responsible for this disorder through instructions sent to the body by the nervous system. The silhouette effect is thus shown to be a cybernetic disorder as opposed to a functional one. The existence of unexpected information-and-semantic pathways throughout the human body is also revealed by this spontaneous transition.

A reactive-homeostasis model is then proposed in which symptoms result from an abnormal but coherent regulation of the functioning of the body caused by an unconscious mechanism by the brain to escape paradoxical realities. Spontaneous recovery is then a consequence of the paradoxical situation dissolution induced by the pregnancy announcement.

This concept of reactive-homeostasis prompts us to investigate human disorders in complementary categories; i.e. cybernetic versus functional. Such an enlarged point of view may improve our knowledge of aetiology and suggest new perspectives for therapeutics research.
\end{abstract}




\section{DENIAL OF PREGNANCY AND THE SILHOUETTE EFFECT}

\subsection{Introduction to denial of pregnancy}

Denial of pregnancy is a woman's subjective lack of awareness of being pregnant(1). Denial is defined as a primitive defence mechanism found not only in psychotic patients but also in healthy individuals under unusually severe stress. Its aim is to alleviate unpleasant affects by disavowing aspects of reality(2,3). Denial of pregnancy can last for months or even until the unexpected 'sudden' delivery of the baby. In the latter case, significant risk to the infant and mother may result, such as poor nutrition, foetal abuse, unattended or precipitous delivery, maternal postpartum emotional disturbance, and neonaticide(4). Wessel et al. report an incidence of $1 / 475$ for unawareness of pregnancy after the 20th week of gestation and 1/2455 for totally unexpected births from a one year study in the Metropolitan Berlin area(5). Miller describes denial of pregnancy in three different categories: affective, pervasive and psychotic(6). There is no clear dividing line between conscious coping and unconscious defence mechanisms but there is a fluid transition described as "middle knowledge"(3,7). Spielvogel confirms that persistent denial of pregnancy occurs in women with otherwise intact reality testing(4).

In the case of pervasive denial of pregnancy, women frequently do not experience the physical changes of pregnancy such as morning sickness, cessation of menstruation, excessive weight gain and foetal movements(3,4,6-11). For instance, an 18 year-old woman delivered a $3 \mathrm{~kg}$ newborn with breach presentation when she came to the hospital complaining of appendicitis. Two weeks earlier, this woman spent a holiday on a naturist beach. In spite of being naked, no-one in her surroundings suspected she was pregnant(7).

\subsection{Silhouette effect and clinical observations}

Throughout this work, we are interested in particular cases of pervasive denial of pregnancy in which the three following conditions are present:

- C1: absence of abdominal swelling at the time of denial,

- C2: pregnancy revealed before delivery during a visit to a physician, 
- C3: abdominal swelling taking place spontaneously after the pregnancy announcement.

Nisand explains how abdominal swelling can be absent, even at the end of pregnancy(12). Instead of taking place horizontally and thus causing abdomen prominence, the fetus expands itself in the vertical direction to the detriment of the diaphragm, thus allowing the silhouette to remain slim. Abdominal muscles are involved in this disorder to maintain a flat abdominal shape. After pregnancy denial disclosure, Nisand explains that the fetus takes up a normal position; horizontally. Then abdominal swelling appears as the muscles relax. This spontaneous bodily transformation following the denial disclosure is what we call here the silhouette effect of denial of pregnancy. This silhouette effect has been observed by different clinicians $(9,12-14)$ and seems to be a frequent consequence of announcing her pregnancy to a woman in denial of pregnancy. Evidence has been reported by more than ten women who have experienced this(11,15).

Let us describe two cases as typical examples: Rozan reports on a young woman who consulted him while in denial of a 7 month pregnancy without any silhouette transformation(14). The practitioner detected her pregnant state and confirmed his diagnosis by means of an ultrasound examination. After the announcement the woman was surprised but happy. Still naked she moved from the examination table to sit in front of the physician. Then she asked for confirmation: Is it actually mine, the baby? Rozan confirmed her gravid state and when the woman stood up again to get dressed he had almost a different woman before him. A few minutes before, the pregnancy had not been noticeable from her silhouette while now, standing in a different posture, leaning backwards slightly, her abdomen was prominent. Rozan reports with surprise this complete physical metamorphosis that had taken place so quickly because of her psyche.

The case of S. Luna is another striking example(15). This woman participated in a TV program that she eventually won, in which young singers competed. In the final TV show, she was singing and dancing while already 5 months pregnant. She was still unaware of her pregnancy as were the production team and millions of TV viewers. Her pregnancy was discovered in the 6th month while she still had not gained any weight. Between denial disclosure and delivery, she finally put on $18 \mathrm{~kg}$ of 
which $5 \mathrm{~kg}$ during the week following the announcement. She also felt foetal movements for the first time during the night following her pregnancy announcement.

In scientific work, denial of pregnancy has been first and foremost studied because of the risks for the mother and the newborn's health, especially in the case of unexpected deliveries(16-18). From a medical point of view such as this and unlike in unexpected deliveries, the silhouette effect is only a curiosity when it has no actual consequences. This is probably the reason why it is usually not reported in the literature on denial of pregnancy. In practice, it may be more difficult to source accounts of the silhouette effect in scientific papers than in memoirs $(11,15)$ or in videos available on the internet.

\section{SYSTEM-BASED ANALYSIS OF THE SILHOUETTE EFFECT}

\subsection{Cybernetic versus functional disorders}

Let us apply an elementary system-based analysis to the set of conditions $\mathbf{C 1}$ through $\mathbf{C 3}$. C1 and $\mathbf{C 3}$ are the successive output states of the body; respectively abnormal and normal; while $\mathbf{C 2}$ is the input signal triggering the spontaneous transition from $\mathbf{C 1}$ to $\mathbf{C 3}$. From a physiological point of view, let us consider the case of abdominal muscles that are in a steady state of contraction in $\mathbf{C 1}$ whereas they are relaxed in $\mathbf{C 3}$. The presence of $\mathbf{C 3}$ demonstrates unambiguously that abdominal muscles in this case are perfectly functional. Any functional inability of the body to behave normally has thus to be excluded as a cause of $\mathbf{C 1}$. It is therefore evident that the abdominal muscle contraction observed in $\mathbf{C 1}$ results from instructions received from the nervous system that ask them to remain contracted.

These elementary considerations of clinical observations establish clearly that the silhouette effect of denial of pregnancy corresponds to a cybernetic disorder rather than to a functional one. According to Wiener's book title 60 years ago, cybernetics stands here for communication between elements of a controlled system(19). It is remarkable that this cybernetic disorder is cured by a piece of information; i.e. the pregnancy announcement. This spontaneous recovery, reported many times(1115), is evidence that, at least in this case, the assimilation of a piece of verbal information can induce involuntary bodily transformations and heal the disorder. 
This distinction between cybernetic and functional disorders is somewhat similar to the distinction between software and hardware problems in the computer domain. Just as software problems can be solved by software solutions, the silhouette effect is a cybernetic disorder that can be cured by a cybernetic solution.

\subsection{Information pathways throughout the human body}

The silhouette effect of denial of pregnancy reveals the existence of active information links between different levels of the human nervous system:

i) the psyche responsible for pregnancy denial(18),

ii) the autonomous nervous system controlling the abdominal muscles,

iii) and the functions of the cerebral cortex in charge of language.

The physiological impact of denial of pregnancy is even deeper since pregnancy symptoms are commonly absent in those women(3,4,6,8,10,11). In the Brezinka study(3) for instance, of the 11 women whose denial ended only during labour or delivery, none experienced nausea or related symptoms. This $0 \%$ observation is far from the normal rate of between $56 \%$ and $85 \%(20-22)$. While the aetiology of nausea of pregnancy is not fully agreed upon, it is commonly accepted that it results from human adaptation and involves the human chorionic gonadotropin hormone secreted by the placenta(21,23). Nausea as a pregnancy symptom is thus associated with hormonal processes that are among the most primitive and subtle physiological mechanisms occurring within the human body. The abnormal observations of Brezinka suggest that either these subtle processes or their effects on the human body might be inhibited in the case of denial of pregnancy where the origin is psychic. This result is surprising since no psychic problem would have been anticipated to act at such a basic physiological level. A corollary implication is that it would be very speculative to exclude a priori a psychic cause from any physiological disorder. It is therefore important to consider the cybernetic approach discussed above. This recommendation was already expressed differently thirty years ago by H. Laborit: "All dichotomy between man and his environment, between the psychic and the somatic, seems to hark back to some prehistoric era of biology, to a time when thermodynamics dominated scientific research and a formal notion of information did not yet exist"(24). 


\section{REACTIVE-HOMEOSTASIS AS A CYBERNETIC MODEL}

There is an obvious relationship in meaning between the pregnancy announcement and the disorder being cured spontaneously. However at this point we do not have any explanation as to why or how this announcement triggers the spontaneous bodily transformation observed. To explore this issue, let us consider the actual significance of the pregnancy announcement:

At some level of the autonomous nervous system, pregnancy is necessarily "known" through information issued by the sensory system. Therefore the pregnancy announcement cannot be considered directly as "new information" liable to trigger changes. For the conscious mind, on the contrary, the woman who was unaware in $\mathbf{C 1}$ becomes aware of her gravid state through the pregnancy announcement. This is indeed an actual change but the latter concerns the conscious mind rather than the autonomous nervous system controlling the abdominal muscles. Therefore abdominal swelling appearing spontaneously after denial disclosure cannot be a direct consequence of this announcement. Some kind of communication between the conscious mind and the autonomous nervous system is necessarily involved in the bodily transformation observed. We do not have a watertight explanation for this phenomenon. However, let us introduce a reactive-homeostasis model that is consistent with the observations.

The aim of denial is to alleviate unpleasant affects by disavowing aspects of reality $(2,3)$. In the case of pregnancy denial, we may say that the women concerned are not "allowed" by their psyches to be pregnant even though they physiologically are pregnant. Denial may thus be seen as a contrived way to respect both of these paradoxical realities. The solution to this is a "secret" pregnancy, one that exists below the woman's awareness. In this model the absence of pregnancy symptoms have to be considered as resulting from an unconscious but coherent mechanism aimed at hiding the gravid state rather than from any functional failure. The absence of abdominal swelling is thus compatible with the ability of the body to function normally by responding to a reactive-homeostasis. The latter is induced by the central nervous system in order to comply with these paradoxical realities. 
The pregnancy announcement constitutes an infringement of the psychic "ban" on being pregnant. The psychic problem is thus transformed. Instead of respecting the pregnancy prohibition, the mind has then to deal with its transgression. The new situation is not necessarily easier to face but the paradoxical block has been removed. The escape mechanism thereby loses its relevance and can then be released, allowing abdominal swelling to take place. From this perspective, the cybernetic disorder has to be seen as an adaptive mechanism of the nervous system to manage an unsolvable situation. Thus the body, as a way of dealing with its paradoxical realities, enters a state of reactivehomeostasis, inducing the appearance of symptoms.

Let us consider additional observations on this model of reactive-homeostasis:

In the case of pregnancy denials lasting until unexpected deliveries, the abdominal and thoracic cavities are reduced by several litres in available volume while hosting several kilograms of weight. Despite this level of bodily transformation, much larger than a heavy meal, the women concerned do not feel poorly and can keep up their usual lifestyle. Fatigue and irritability are the only symptoms reported in the final weeks of gestation. For instance, since the fetus is lying vertically, the diaphragm is displaced upwards to a significant degree. With such a constraint imposed on this respiratory muscle, no breathing difficulties have been reported, neither in scientific papers nor in women's life stories. These observations would suggest that these internal bodily transformations are managed by some kind of adaptive process to allow a satisfactory functioning; thus supporting the reactivehomeostasis model.

Since pregnancy has a finite duration, this tactic of hiding it will necessarily fail at some point; i.e. when labour and delivery take place. While this final failure is certain, denial is maintained until the very end in many cases. This contradiction seems incompatible with a coherent mechanism. However this is no longer the case if the reactive-homeostasis state is considered as a reflexive mechanism enabling the immediate escape from an emergency situation. As with all reflexes, the reactive-homeostasis state has to be considered as an automatic and uncontrolled response to a particular emergency state, without any temporal or future considerations. From this perspective, denial persistence results from the emergency state being upheld, which itself results from the 
persistence of paradoxical realities. The continued denial of pregnancy until an unexpected delivery is thus compatible with the reactive-homeostasis model proposed. We may observe that this configuration is comparable to what is called "standby in tension" as proposed by Laborit in the concept of inhibition of action(24,25) (or behavioural inhibition).

\section{DISCUSSION}

Since its introduction in the middle of the last century, cybernetics has been applied very successfully within the domain of machines. One direct consequence is that our everyday life has been deeply transformed in western countries. From the very beginning, cybernetics has been considered as beneficially applicable to animals and humans(19). However, many fewer advances have been reported in the domain of living organisms. One obvious reason is that the study of interactions within a system assumes an extensive knowledge of its internal states. In the case of living systems, this condition is hard to meet due to the huge number of parameters to consider and to the impossibility of accessing most of them. Furthermore, inter-individual differences, either due to genetics, lifeexperiences or environment, mean that comparisons between living individuals are much less representative that in the case of identical machines. In this context, the silhouette effect of denial of pregnancy is a notable exception. Since the transition between $\mathbf{C} \mathbf{1}$ and $\mathbf{C} \mathbf{3}$ occurs in a short period of time starting at the doctor's office, unknown parameters remain necessarily unchanged and can thus be discarded from the cybernetic analysis. Thanks to this particularity of the silhouette effect, a clear cause-and-effect relationship can be established between the pregnancy announcement and the spontaneous appearance of abdominal swelling. It is thus clear that the silhouette effect is a cybernetic disorder induced by the brain instead of a functional one. Furthermore, the few words announcing the pregnancy to the formerly unaware woman act as a cybernetic solution; i.e. an effective cure triggering spontaneous recovery. The existence of information-and-semantic pathways throughout the human body is also revealed by this analysis.

A reactive-homeostasis model has been proposed to explain this phenomenon. From this perspective, the symptoms observed result from a reflexive mechanism induced by the unconscious mind in response to a paradoxical situation. This concept is analogous to that of "standby in 
tension"(24,25). It can also be compared to the "double-bind" concept introduced by Bateson et al.(26) in the study of schizophrenia. Instead of the paradoxical injunctions considered by Bateson at an interindividual communication level, our model involves paradoxical realities at the intra-individual level.

Physical and psychosocial stresses are known to induce somatic disorders for a long time, especially on the digestive tract $(27,28)$. The silhouette effect of denial of pregnancy discussed here may be considered as being in the same family of processes. However its capacity to be solved by a cybernetic solution consisting only of a few words is a new and specific property of which the implications have to be explored and discussed in the future.

In a time lapse of only a few generations, human lifestyles have changed considerably in western countries. While physically demanding activities are fortunately diminishing, professional and psychosocial stresses are increasing. Fatigue of the human condition is thus progressively shifting from physical pains affecting the body directly towards environmental stresses affecting the body indirectly through the central nervous system. Consequently, one may expect public health systems nowadays to address a decreasing proportion of functional disorders but an increasing proportion of cybernetic disorders. Because of this modern evolution of humanity, health and its mental or physiological disorders have to be considered through supplementary approaches. These should be global, exploring the human body as an integrated system controlled by complex information-andcommunication processes subject to weaknesses, failures or paradoxical blocks. The basis of such a cybernetics approach can be found in previous works and concepts set out by such prestigious pioneers as Bernard(29), Cannon(30), Selye(31) or Laborit(24,31). This way of thinking is however very recent in comparison with the thousand-year-old history of medicine and further investigation of how cybernetics can help to understand human disorders may be beneficial.

\section{Acknowledgements}

The author acknowledges Belinda Lafon for bibliographic assistance and Sharon Black for manuscript revision. 


\section{References}

1 Wessel J., Gauruder-Burmester A., Gerlinger C., Denial of pregnancy-characteristics of women at risk, Acta Obstet. Gynecol. Scand. 86, 542-546 (2007).

2 Vaillant G.E, Theoretical hierarchy of adaptative ego mechanisms, Arch. Gen. Psychiatr. 24, 107-118 (1971).

3 Brezinka C., Hueter O., Biebl W., Kinzl J., Denial of pregnancy: obstetrical aspects, J. Psychosom. Obstet. Gynecol. 15, 1-8 (1994).

4 Spielvogel A.M., Hohener H.C., Denial of pregnancy: A review and case reports, Birth 22, 220-226 (1995).

5 Wessel J., Endrikat J., Buscher U., Frequency of denial of pregnancy: results and epidemiological significance of a 1-year prospective study in Berlin, Acta obstet. Gynecol. Scand. 81, 1021-1027 (2002).

6 Miller L.J., Denial of pregnancy, in Infanticide: psychosocial and legal perspectives on mothers who kill, M.G. Spinelli ed., 81-104 (Am. Psych. Pub 2003).

7 Brezinka C., A propos des données épidémiologiques, Actes du premier colloque français sur le déni de grossesse, 15-23 (Ed. Univ. du Sud 2008).

8 Brozowsky M., Falit H., Neonaticide: Clinical and psychodynamic considerations, J. Am. Acad. Child Psychiatry 10, 673-683 (1971).

9 Bascom L., Women who refuse to believe: persistent denial of pregnancy, Am. J. of Maternal/Child Nursing 2 , 174-177 (1977).

10 Wessel J., Endrikat J., Cyclic menstruation-like bleeding during denied pregnancy. Is there a particular hormonal cause?, Gynecol. Endocr. 21, 353-359 (2005).

11 AFRDG, déni de grossesse ; 99 histoires vécues, (Amalthee ed. 2010).

12 Nisand I., in Déni de grossesse, ces bébés clandestins, documentary by A. Rawlins Gaston (Capa productions 2008).

13 Lolo B., Déni de grossesse : Quand le psychisme occulte une partie du corps ; Discussion anthropopsychanalytique, Actes du premier colloque français sur le déni de grossesse, 197-207 (Ed. Univ. du Sud 2008).

14 Rozan M.A., L’obstétricien et le déni de grossesse, Actes du premier colloque français sur le déni de grossesse, 41-45, (Ed. Univ. du Sud 2008).

15 Luna S., T'étais déjà là mon fils, mais... histoire d'un déni de grossesse, 159-169 (M. Laffon 2009).

16 Friedman S.H., Henegan A., Rosenthal M., Characteristics of woman who deny or conceal pregnancy, Psychosomatics 48, 117-122 (2007). 
17 Lee A.C.W., Li C.H., Kwong N.S., So K.T., Neonaticide, newborn abandonment, and denial of pregnancynewborn victimisation associated with unwanted motherhood, Hong Kong Med. J. 12, 61-64 (2006).

18 Spinelli M.G., Denial of Pregnancy: A Psychodynamic Paradigm, J. Am. Acad. Psychoanal. Dynam. Psychiatry 38, 117-131 (2010).

19 N. Wiener, Cybernetics or control and communication in the animal and in the machine, (The technology press 1949).

20 Klebanoff M.A., Koslowe P.A., Kaslow R., Rhoads G.G., Epidemiology of vomiting in early pregnancy, Obstetr. Gynecol. 66, 612-616 (1985).

21 Davis M., Nausea and vomiting of pregnancy: an evidence-based review, J. Perinat. Neonatal. Nurs. 18, 312$328(2004)$

22 Pepper G.V., Craig Roberts S., Rates of nausea and vomiting in pregnancy and dietary characteristics across populations, Proc. R. Soc. Lond. B Biol. Sci., 273, 2675-2679 (2006).

23 Sherman P.W., Flaxman S.M., Nausea and vomiting of pregnancy in an evolutionary perspective, Am. J. Obstet. Gynecol. 186, S190-197 (2002).

24 Laborit H., L'inhibition de l'action, 1st ed. (Masson 1979). Citation in french : "Toute dichotomie de l'homme et de son environnement, du psychique et du somatique, nous paraît ressortir d'une préhistoire de la biologie, à l'époque où la thermodynamique dominait la recherche scientifique dans l'ignorance de la notion d'information", p.136.

25 Laborit H., The major mechanisms of stress, in Stress revisited 2. Systemic effects of stress, Jasmin G. and Proschek L. ed., Methods Achiev. Exp. Pathol. 15, 1-26 (1991).

26 Bateson G., Jackson D.D., Haley J., Weakland J.H., Toward a theory of schizophrenia, Behav. Sci. 1, 251-264 (1956).

27 H. Selye, The general adaptation syndrome and the diseases of adaptation, J. Clin. Endocrinol. Metab. 6, $117-230(1946)$.

28 Caso J.R., Leza J.C., Menchen L., The effects of physical and psychological stress on the gastrointestinal tract: lessons from animal models, Curr. Mol. Medic. 8, 299-312 (2008).

29 Bernard C., Leçons sur les phénomènes de la vie communs aux animaux et aux végétaux, (Baillière 1879).

30 Cannon W.B., The wisdom of the body, (WW Norton and Co. Inc. 1932).

31 Laborit H., On the mechanism of activation of the hypothalamo-pituitary-adrenal reaction to changes in the environment (the "alarm reaction"), Resuscitation 5, 19-30 (1976). 